\title{
Topical Effect of Glutamine for Colorectal Anastomosis
}

\author{
Jong-Woo Kim \\ Department of Surgery, CHA Bundang Medical Center, CHA University, Seongnam, Korea
}

\section{See Article on Page 213-221}

Glutamine is one of 20 amino acids and is most abundant in human blood. The liver is its main regulatory organ, and it is mainly stored in muscles. The intestine, intestinal epithelial cells and lymphoid cells, is one of its biggest consumers. It encourages mucosal growth and repair, improves mucosal atrophies and functions, and is needed in catabolic, inflammatory or postoperative states. Catabolic patients improve when given glutamine-rich nutrient supplements $[1,2]$.

The nutritional or trophic effect of glutamine for anastomotic healing has been demonstrated by several studies. One experimental study showed improved healing of a colonic anastomosis with early enteral nutrition with glutamine-enriched formulas. Also, different suggestions have been made about the use of parentallyadministrated glutamine solutions for a colonic anastomosis, but this positive effect of glutamine is just based on systemic support through intravenous or enteral administration [3-5].

The local or topical effect of glutamine is only for inflammations of the colon such as chronic inflammatory bowel disease, radiation proctitis, so on. This seems to be the antioxidant effect of glutamine, and it is mediated by glutathione, one of the major antioxidants. Glutamine is actually a substrate for the synthesis of glutathione. Many studies support a protective effect of glutamine administration in the treatment of colitis via a local route or systemically [6]. However, so far, no report has verified the local or topical effect of glutamine to ensure a normal anastomosis of the colon. This is the only experimental article to demonstrate its local effect via the enema route for the normal anastomotic healing process. Moreover, because this study tried to show objectively the positive effects of glutamine on the anastomosis, it is worth-

Correspondence to: Jong-Woo Kim, M.D.

Department of Surgery, CHA Bundang Medical Center, CHA University, 59 Yatap-ro, Bundang-gu, Seongnam 13496, Korea

Tel: +82-31-780-5250, Fax: +82-31-780-5259

E-mail: kjw@cha.ac.kr

(C) 2015 The Korean Society of Coloproctology

This is an open-access article distributed under the terms of the Creative Commons Attribution NonCommercial License (http://creativecommons.org/licenses/by-nc/3.0) which permits unrestricted noncommercial use, distribution, and reproduction in any medium, provided the original work is properly cited. while [7].

As we know, in normal anastomotic healing, there is no regeneration of smooth muscle, but just scarring with a collagen deposit following the inflammation stage. Thus, the healing of a normal anastomosis must involve an inflammatory process, but we know that not much inflammation exists at the normal anastomotic site of the bowel, as in inflammatory bowel disease (IBD) and radiation enteritis. In addition, the positive effect of glutamine on a normal anastomosis cannot be explained by its anti-inflammatory or antioxidant effects; thus, some questions exist. The effect of glutamine in reducing inflammation might delay the actual normal anastomotic healing process. Even an enema can physically affect the anastomotic healing process. Moreover, the mucosa on the anastomotic site may heal and be epithelialized at the earliest in a day; after which mucin is normally excreted from the normal regenerating epithelium and covers the epithelium itself. Actually, mucin, co-working with trefoil factors and other molecules, provides stronger protection for the mucosa epithelium. Here, we can hardly anticipate the ability of the mucosa epithelium to absorb glutamine that was introduced via an enema route. Thus, we expect the effect of glutamine on normal anastomotic healing to be local. Therefore, we should differentiate the local or topical effect of glutamine from its systemic effect. The systemic positive effect of glutamine was mentioned above [8]. Although questions might exist, this study showed positive results for glutamine having a local effect on the anastomosis; however, it did not explain the mechanism behind that effect. We have to wait for further studies for that answer. I also hope that glutamine will turn out to be promising for a normal anastomosis, not only systemically but also topically.

Before ending this editorial, I would like to remind the reader of the cardinal principles of anastomosis that we should adhere to up while making an anastomosis: avoid tension across the anastomosis, ensure good blood supply to both bowel ends, achieve a watertight apposition of both edges, no sepsis or gross contamination, etc. Hence, we assume that all the positive effects of glutamine on an anastomosis should be based on these crucial principles of anastomosis.

A glutamine enema might be an alternative helpful choice for the anastomosis, but not yet; more positive evidence is still needed. Last but not least, I will ask the readers this question: In 
the situation of uncertainty where you are not sure if the colonic anastomosis is secure, do you make an ileostomy or proximal colostomy for fecal diversion, or do you use a glutamine enema before leaving the operation room?

\section{CONFLICT OF INTEREST}

No potential conflict of interest relevant to this article was reported.

\section{REFERENCES}

1. Tannuri U, Carrazza FR, Iriya K. The effects of glutamine-supplemented diet on the intestinal mucosa of the malnourished growing rat. Rev Hosp Clin Fac Med Sao Paulo 2000;55:87-92.

2. Oguz M, Kerem M, Bedirli A, Mentes BB, Sakrak O, Salman B, et al. L-alanin-L-glutamine supplementation improves the outcome after colorectal surgery for cancer. Colorectal Dis 2007;9:515-20.

3. Güven A, Pehlivan M, Gokpinar I, Gurleyik E, Cam M. Early glutamine-enriched enteral feeding facilitates colonic anastomosis healing: light microscopic and immunohistochemical evaluation. Acta Histochem 2007;109:122-9.

4. Donmez R, Oren D, Ozturk G, Kisaoglu A, Ozogul B, Atamanalp SS. The combined effects of glutamine and growth hormone on intestinal anastomosis in the rat intra-abdominal sepsis model. J Surg Res 2013;182:142-5.

5. Demetriades H, Botsios D, Kazantzidou D, Sakkas L, Tsalis K, Manos K, et al. Effect of early postoperative enteral feeding on the healing of colonic anastomoses in rats. Comparison of three different enteral diets. Eur Surg Res 1999;31:57-63.

6. Fillmann H, Kretzmann NA, San-Miguel B, Llesuy S, Marroni N, González-Gallego J, et al. Glutamine inhibits over-expression of pro-inflammatory genes and down-regulates the nuclear factor kappaB pathway in an experimental model of colitis in the rat. Toxicology 2007;236:217-26.

7. Habibi M, Oner OZ, Oruc MT, Bulbuller N, Ozdem S, Ozdemir S, et al. Effects of a glutamine enema on anastomotic healing in an animal colon anastomosis model. Ann Coloproctol 2015;31:213-21.

8. Wright NA. Interaction of trefoil family factors with mucins: clues to their mechanism of action? Gut 2001;48:293-4. 